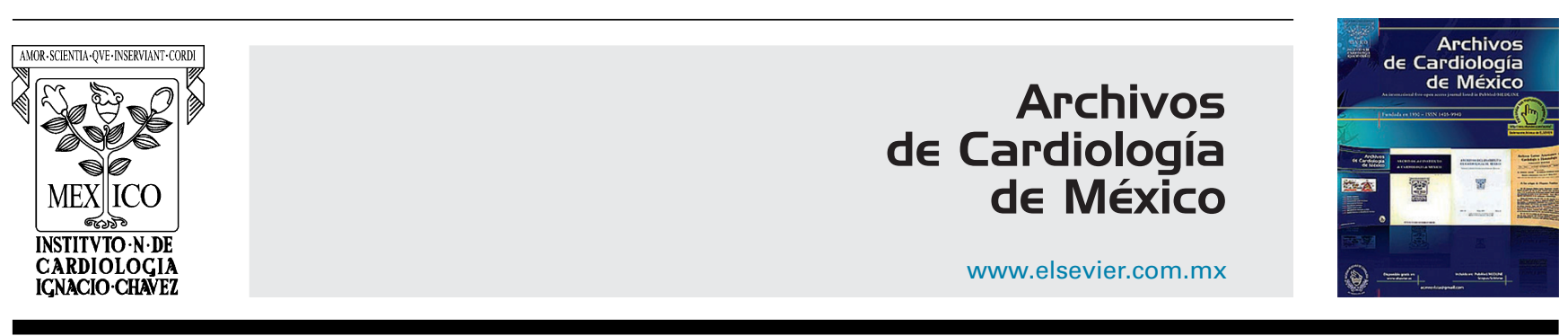

IMAGEN EN CARDIOLOGÍA

\title{
Abordaje dual para ablación de flutter auricular atípico después de cirugía de Mustard
}

\section{Dual approach for atypical atrial flutter ablation after the Mustard procedure}

\author{
Javier Burgoa-Vargas*, Santiago Nava-Townsend, Mirna Alvarez-Bran, \\ José Batarse-Rivera y Pedro Iturralde-Torres
}

Departamento de Electrofisiología Cardiaca, Instituto Nacional de Cardiología Ignacio Chávez, Ciudad de México, México

Recibido el 18 de julio de 2017; aceptado el 26 de diciembre de 2017

La arritmia cardiaca más frecuente posterior a la cirugía de Mustard es el flutter auricular, que en su mayoría tiene como componente crítico el istmo cavotricuspideo (ICT), mismo que se encuentra dividido por el deflector intraauricular en una porción «sistémica» y otra venosa «pulmonar». El objetivo de la ablación del flutter es el bloqueo bidireccional del ICT, por lo que en estos casos se presenta una dificultad técnica obvia. El abordaje dual, con ablación del istmo «sistémico» e istmo «pulmonar» es una buena opción para lograr el bloqueo bidireccional del ICT en pacientes con corrección tipo Mustard ${ }^{1,2}$.

Se presenta el caso de un paciente masculino de 12 años de edad, quien fue diagnosticado desde el nacimiento de transposición clásica de grandes arterias, operado a los 14 meses de vida de cirugía de Mustard. A los 11 años de edad presenta episodios de palpitaciones rápidas que correspondían a flutter auricular atípico (fig. 1A) paroxístico sintomático. Se realiza estudio electrofisiológico en ritmo sinusal con sistema de mapeo electroanatómico $3 \mathrm{D}$ (CARTO ${ }^{\circledR}$ 3 System, BiosenseWebster) e integración

\footnotetext{
* Autor para correspondencia. Juan Badiano n. ${ }^{\circ} 1$. Col. Seccción XVI. Tlalpan, CP. 4080 México, DF, Teléfono-Fax: +00 (52)155133740. Correo electrónico: jburgoa1@hotmail.com (J. Burgoa-Vargas).
}

anatómica con angiotomografía computada para mejor correlación anatómica. Por vía venosa femoral se avanzó catéter duodecapolar abarcando vena cava inferior y vena cava superior y un catéter decapolar a la zona adyacente al deflector intraauricular correspondiente al ICT «pulmonar», el catéter de ablación (NAVISTAR ${ }^{T M}$ THERMOCOOL $^{\circledR}$, BiosenseWebster) se avanza tanto por vía venosa femoral para la ablación del ICT venoso «pulmonar» y posteriormente por vía retrógrada aórtica a ventrículo derecho pasando por la válvula tricúspide para posicionarse en el ICT «sistémico» (fig. 1B); se realiza reconstrucción anatómica y de voltaje de ambas porciones auriculares e integración con la tomografía. Mediante estimulación a ambos lados del istmo se identifica conducción a nivel del mismo. Se realizó ablación inicialmente en el istmo pulmonar y una línea entre ambas venas cavas y, posteriormente, bajo estimulación con el catéter decapolar en el ICT «pulmonar» se completa la ablación, hasta alcanzar el bloqueo bidireccional vía retrógrada en el ICT «sistémico» (fig. 2A-E), sin lograr reinducción del flutter. En el mismo procedimiento se documenta disfunción de nodo sinusal y por vía venosa subclavia derecha se implanta marcapasos Medtronic ${ }^{\circledR}$ de doble cámara con un electrodo en el techo de aurícula izquierda «venosa» y el segundo electrodo en ápex del ventrículo izquierdo dejando asa ventricular con adecuados parámetros tanto de detección como de captura en ambos electrodos, quedando con 
A

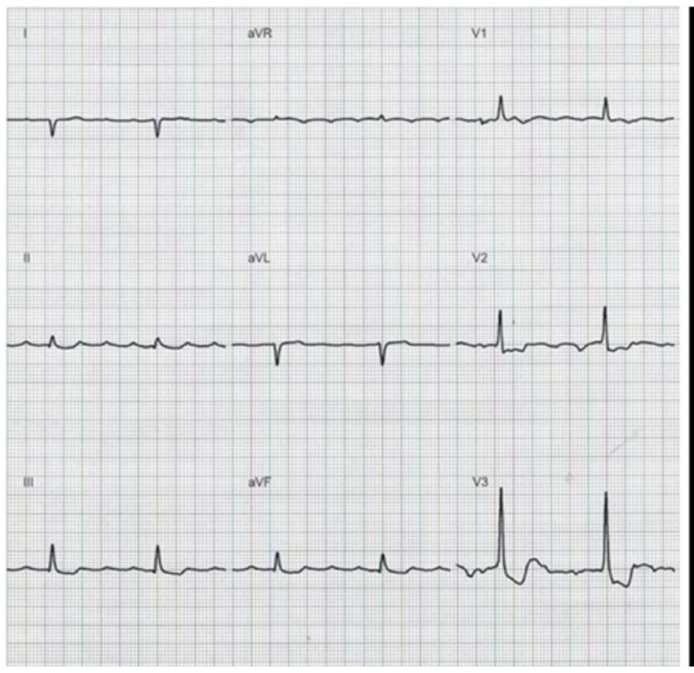

B

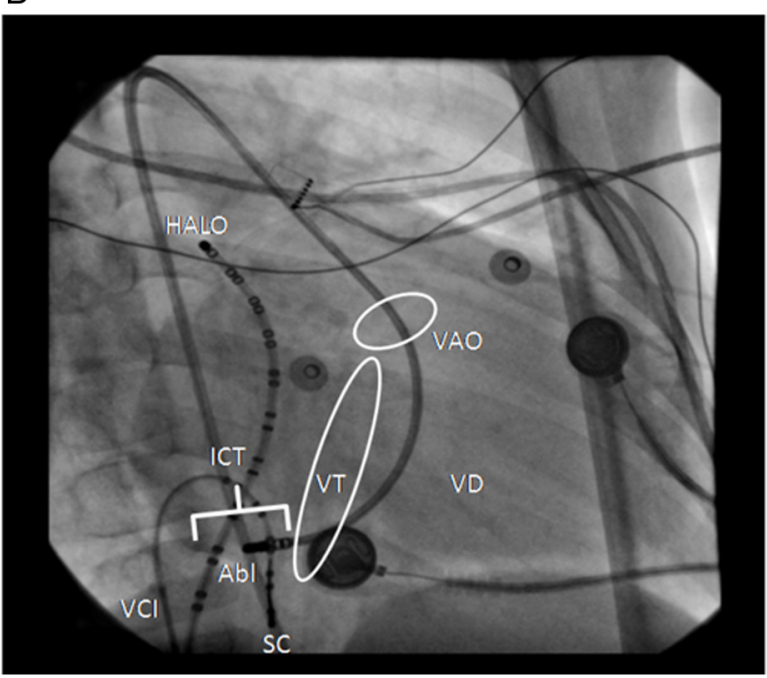

Figura 1 A. Electrocardiograma de paroxismo de flutter auricular 4:1 con ondas «F» positivas en derivadas inferiores y de mayor voltaje con relación a precordiales. Frecuencia ventricular 54 lpm. B. Proyección oblicua anterior derecha con catéter de ablación en ICT «sistémico» vía retroaórtica.

A

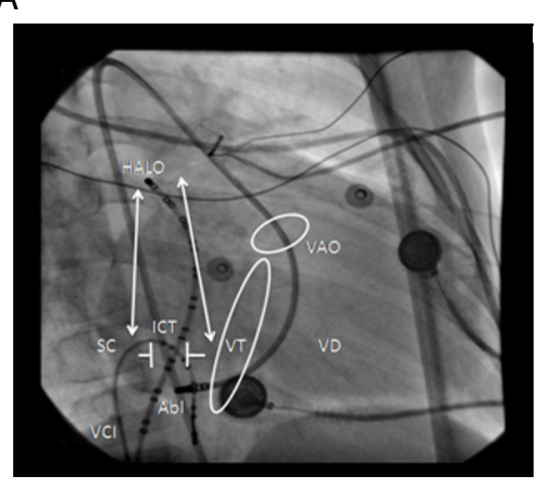

B

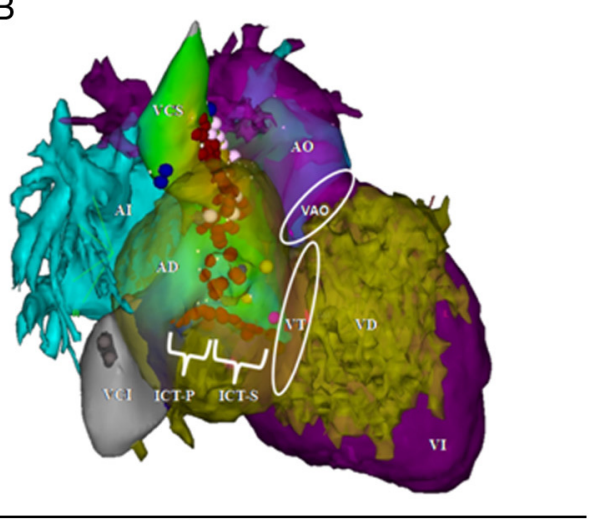

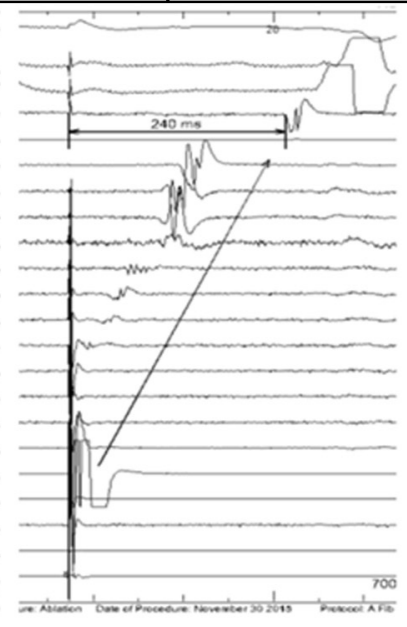

D

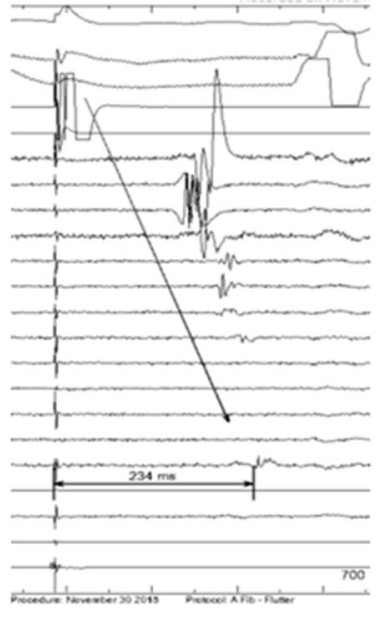

E

Figura 2 A. Proyección oblicua anterior derecha, con catéter decapolar (SC) en extremo venoso «pulmonar» y catéter de ablación (Abl) en extremo «sistémico» del ICT. B. Mapeo electroanatómico 3D, proyección oblicua anterior derecha con línea de ablación (puntos rojos) completa a nivel del ICT. C. Conducción patente a través del ICT estimulando desde catéter SC en istmo venoso hasta catéter de ablación en istmo sistémico con $78 \mathrm{~ms}$ de activación entre ambos lados del ICT preablación. D. Conducción a través del ICT postablación con estimulación en ICT venoso (SC 5-6) hasta catéter de ablación en ICT sistémico con activación de 240 ms. E. Conducción a través del ICT postablación con estimulación en ICT sistémico desde catéter de Abldx hasta registro en ICT venoso en catéter SC con $234 \mathrm{~ms}$ de activación. 
modo de estimulación DDDR. A 3 meses de seguimiento el paciente no ha presentado recurrencia de la taquicardia ni disfunción del marcapasos.

El abordaje dual permite el bloqueo bidireccional del ICT, en pacientes con flutter auricular operados de cirugía de Mustard. El mapeo electroanatómico 3D con integración de imagen tomográfica facilita la identificación de las estructuras claves para la ablación con abordaje retroaórtico en lugar de la punción transdeflector para el bloqueo del ICT'.

\section{Bibliografía}

1. Balaji S, Stajduhar KC, Zarraga IG, et al. Simplified demonstration of cavotricuspid isthmus block after catheter ablation in patients after Mustard's operation. Pacing Clin Electrophysiol. 2009;32:1294-8.

2. Brugada J, Blom N, Sarquella-Brugada G, et al. Pharmacological and non-pharmacological therapy for arrhythmias in the pediatric population: EHRA and AEPC-Arrhythmia Working Group joint consensus statement. Europace. 2013;15:1337-82. 